\title{
The Use of Activated Alumina and Magnetic Field for the Removal Heavy Metals from Water
}

\author{
Ewa Szatyłowicz ${ }^{1 *}$, Iwona Skoczko' \\ 1 Department of Technology and Systems of Environmental Engineering, Bialystok University of Technology, \\ 45A Wiejska St., 15-351 Białystok, Poland \\ * Corresponding author's e-mail: e.szatylowicz@pb.edu.pl
}

\begin{abstract}
The objective of this work was to verify the granular activated alumina (AA) sorption properties, during the process of removing copper, lead and cadmium from water, and to monitor the impact of magnetic field (MF) on the effectiveness of removing copper, lead and cadmium from water. Activated alumina adsorption is known to be an effective and inexpensive technology for the removal of selenium and arsenic from water, and was suggested by EPA as a BAT for point-of-use applications. The removal of copper, lead and cadmium from water using AA and impact of magnetic field was reported to a lesser extent. Pilot tests showed that the use of AA sorption materials with MF impact could possibly decrease the copper, lead and cadmium content in the model water. The MF also had a positive effect on the efficiency of removal copper, lead and cadmium on AA. Increasing the efficiency of heavy metals removal in the samples exposed to magnetic field varied from $1.9 \%$ to $8.2 \%$ compared to the control samples.
\end{abstract}

Keywords: activated alumina, magnetic field, water treatment, heavy metals

\section{INTRODUCTION}

Recently, the papers containing the laboratory studies on the influence of the magnetic field on the efficiency of adsorption process have been published. The research team of Julian Ferreira de Brito [Ferreira De Brito et al. 2012] tested, under laboratory conditions, the removal of methylene blue and phenol (water contaminants characteristic of the textile industry) by means of adsorption on activated charcoal with additionally applied magnetic field of induction equal to $40 \mathrm{mT}$. The results of their experimental studies have shown that MF increased the efficiency of adsorption in the case of methylene blue and phenol [Ferreira De Brito et al. 2012]. Thus, adsorption at a particular magnetic field induction may be an alternative to the adsorption process itself; it may reduce the need for the adsorbent and increase the efficiency of removal of individual components from an aqueous solution. Another example of weak magnetic field use to increase the sorption capacity of a sorbent by influencing the physicochemical properties of aqueous solutions are the studies by Hao and his research team [Hao et al. 2012] carried out on methylene blue adsorption on magnetic field assisted organic bentonite. These studies related to the effect of an adsorbent dose, initial concentration of pigment, $\mathrm{pH}$ value, magnetic field intensity, and type of magnetic field on methylene blue adsorption. As a result of the experiment, it was proven that PM enhances the adsorption coefficient in the Freundlich model by $49 \%$.

Typically, the adsorption is used for the removal of water soluble organic impurities causing the colour and smell of the water, metals, and anions. The adsorption process is used to remove dissolved organic substances, but also to remove specific micro-pollutants, even impurities, the traces of which may constitute a health hazard or are undesirable in an aqueous solution. The activated carbon is the most common adsorbent, but it is not the only recommended material. One 
of the inorganic sorbents used for removing the components present in water is activated alumina. It is a mixture of amorphous aluminum oxides obtained by dehydrogenation of aluminum hydroxide $\mathrm{Al}(\mathrm{OH})_{3}$ at temperatures of $300-600^{\circ} \mathrm{C}$. The adsorbent has a specific surface area equal to $50-300 \mathrm{~m}^{2} / \mathrm{g}$. It exhibits amphoteric properties, and the parameter indicating its nature is $\mathrm{pH}$, namely $\mathrm{pH}$ of the zero charge, which is 8.2 . In the medium characterized by the $\mathrm{pH}$ below 8.2 , the adsorbent material exhibits anion-exchange properties, and at the $\mathrm{pH}$ above 8.2 - it becomes a cation-exchanger. For example, the mechanism of arsenate ions removal from aqueous solutions of this adsorbent is close to the removing of arsenates on weakly basic anion exchangers [Hering et al. 2004; Mc Neill, Edwards 1995]. Activated alumina is much less likely to be used for water treatment than activated charcoal; however, it is used to remove inorganic contaminants such as fluorides, arsenic, selenium, and silicates. The European Commission has granted activated alumina oxide as an absorbent material for the removal of fluoride ions from water. In addition, adsorption on activated alumina oxide has been proposed by the EPA (Environmental Protection Agency) as an effective and inexpensive technology to remove arsenic and selenium from drinking water, considered among the best available BAT techniques [Davis, Misra 1997; Singh, Pant 2004; EPA 2007; Lin, Wu 2001].

As a result of the analysis on the collected information, it was found that in the future, the influence of magnetic field on the physicochemical properties of water and properties of the sorption materials may be more frequently and widely used, since in many cases, it restricts the use of chemicals and consumption of energy, which contributes to the protection of the natural environment in many aspects. It seems appropriate to investigate the mechanism of magnetic field effect on the process of adsorption on activated alumina. This sorbent has the ability to remove metals, anions, and other specimens present in the water. Furthermore, removal of these components is carried out by adsorption or chemical precipitation of formed hydroxides or complexes. AA is an amphoteric material, and the parameter indicating its character is the $\mathrm{pH}$ of so-called zero point charge (ZPC) amounting to 8.2. In the medium characterized by the $\mathrm{pH}$ below 8.2, this adsorbent material exhibits anion exchange properties, and at the $\mathrm{pH}$ above 8.2 - it becomes a cation- exchanger. Taking into account the characteristics of the activated alumina and the lack of literature references to the studies or tests of magnetic field effect on the ability of sorption by $\mathrm{Al}_{2} \mathrm{O}_{3}$, it seems reasonable to verify and learn about the mechanism of the MF effect on the adsorption process on the sorbent in question. The objective of this work was to verify the granular activated alumina (AA) sorption properties, during the process of removing copper, lead and cadmium from water, and to monitor the impact of magnetic field (MF) on the effectiveness of removing copper, lead and cadmium from water.

\section{MATERIAL AND METHODS}

The study consisted in determining the magnetic field effect on the efficiency of removal copper $(\mathrm{Cu})$, lead $(\mathrm{Pb})$ and cadmium $(\mathrm{Cd})$ with a single component of the model solutions. The experiment was conducted at a laboratory scale using model solutions with the concentration of component of $500 \mu \mathrm{g} / \mathrm{l}$ in the process of dynamic adsorption. The process was carried out with a flow rate equal $61 / \mathrm{h}$. Laboratory tests were performed in a 11 volume of laboratory distributors filled with $\mathrm{Al}_{2} \mathrm{O}_{3}$. Table 1 shows the characteristics of the activated alumina. The dosage of sorbent was $450 \mathrm{~g} / 1$. In parallel, an untreated control sample, which was not exposed to magnetic field, was prepared.

The model solution in polyethylene bottle was exposed for $10 \mathrm{~min}$ to a weak static magnet-

Table 1. Main characteristics of activated alumina

\begin{tabular}{|l|c|c|}
\hline \multicolumn{2}{|c|}{ Appearance } & $\begin{array}{c}\text { White, sphere, } \\
\text { odorless, } \\
\text { insoluble in the } \\
\text { water, unreliable }\end{array}$ \\
\hline Type & KA405 \\
Crystal type & $\mathrm{Al}_{2} \mathrm{O}_{3} \%$ & $\geq 93$ \\
\hline Chemical composition & $\mathrm{Na}_{2} \mathrm{O} \%$ & $\leq 0.3$ \\
\cline { 2 - 2 } LOI & $\%$ & $\leq 8$ \\
Mass density & $\mathrm{G} / \mathrm{ml}$ & $0.75-0.80$ \\
Surface & $\mathrm{m}^{2} / \mathrm{g}$ & $\geq 300$ \\
Pore volume & $\mathrm{ml} / \mathrm{g}$ & $0.30-0.50$ \\
Static absorption, $\mathrm{RH}=60 \%$ & $\%$ & $17-19$ \\
Dew point & $\%$ & $\leq 0.8$ \\
Crushing force (N/pcs) & ${ }^{\circ} \mathrm{C}$ & -40 \\
& $3-5 \mathrm{~mm}$ & $\geq 150$ \\
& $4-6 \mathrm{~mm}$ & $\geq 180$ \\
& $5-7 \mathrm{~mm}$ & $\geq 200$ \\
& $6-8 \mathrm{~mm}$ & $\geq 300$ \\
\hline
\end{tabular}

Source: Safety data sheet from the manufacturer. 
ic field (MF) generated from a stack of magnets $(\mathrm{B}=118 \mathrm{mT})$. The properties of the magnets are shown in Table 2.

The bottle was surrounded by ferrite permanent magnets. Magnetic induction measured through the bottle wall reached $57 \mathrm{mT}$. Ferrite magnets do not require corrosion protection and can be used in water. They are ceramic magnets and, therefore, they are fragile. The measurement of the magnetic induction was performed by means of HGS-10A, an apparatus for induction. A control was also kept for 10 minutes in the same vessel without the MF only in order to eliminate the possible effect of adsorption of the tested component of the water on the walls of the vessel. Subsequently, both samples were filtered through a funnel filled with activated alumina. Figure 1 shows a schematic experiment. The concentration of the test component of the model solution (concentration of $\mathrm{Cu}, \mathrm{Pb}, \mathrm{Cd}$ ) prior to the adsorption process and after the process was determined by means of Thermo Scientific iCE3300 atomic absorption spectrometry apparatus using flame and graphite furnace method.

The experiment was repeated 5 times. These samples were filtered through a column packed with AA. Then, water samples were analyzed for metal concentrations with atomic absorption spectrometry, the electrolytic conductivity, redox potential and $\mathrm{pH}$. In parallel, a sample without the influence of the magnetic field was examined. The obtained results were analyzed statistically. The scope of the statistical analysis included basic measures: the arithmetic mean, median, standard deviation, variance and extreme values of individual components. All calculations and statistical analyzes were performed using the Statistica 12.5 package in the Polish language version of the Windows 10 Home Edition platform.

\section{RESULTS AND DICUSSION}

Pilot tests showed (Table 3 ) that the use of AA sorption materials with MF impact could possibly decrease the copper, lead and cadmium content in the model water. The MF had also a positive effect on the efficiency of copper, lead and cadmium removal on AA.

For each model solution, the lower concentration of the investigated metal was observed in the magnetized samples after the adsorption process, compared to the control samples. After the adsorption process, the electrolytic conductivity

Table 2. Main characteristics of ferrite permanent magnets

\begin{tabular}{|c|c|c|c|c|c|c|}
\hline $\begin{array}{l}\text { Diameter } \\
{[\mathrm{mm}]}\end{array}$ & Height [mm] & $\begin{array}{c}\text { Magnetization } \\
\text { direction }\end{array}$ & $\begin{array}{l}\text { Density } \\
{\left[\mathrm{g} / \mathrm{cm}^{3}\right]}\end{array}$ & $\begin{array}{l}\text { Resistivity } \\
{[\mathrm{Ohm} \times \mathrm{cm}]}\end{array}$ & $\begin{array}{c}\text { Induction of } \\
\text { remanence }[\mathrm{T}]\end{array}$ & Weight [g] \\
\hline $50 \pm 2.5$ & $10 \pm 0.1$ & $\begin{array}{l}\text { along the } 10 \mathrm{~mm} \\
\text { dimension }\end{array}$ & 4.5 & $10^{4}-10^{8}$ & 0.37 & $\sim 88.3$ \\
\hline
\end{tabular}
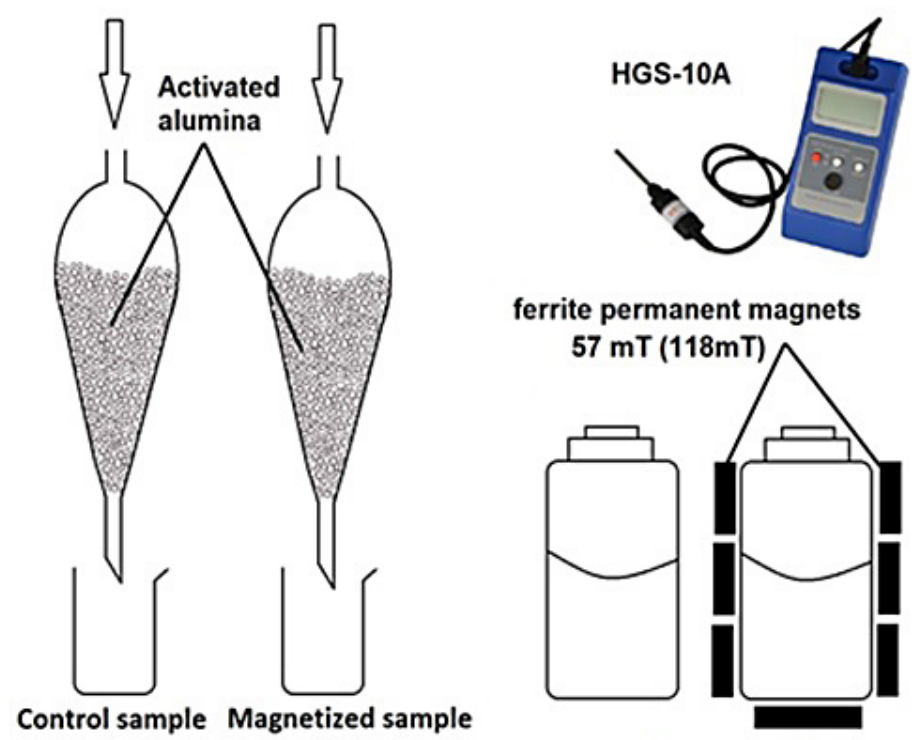

ferrite permanent magnets

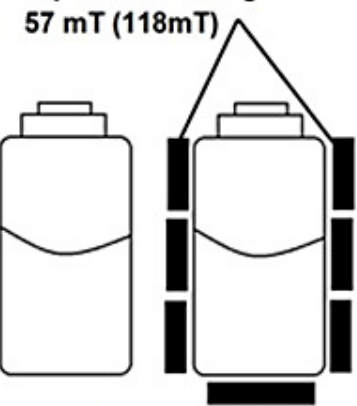

Control sample Magnetized sample

Figure 1. Scheme of equipment used in experiment was the same 
Table 3. The average values with standard deviation of the measured parameters of the samples

\begin{tabular}{|c|c|c|c|c|c|c|c|c|c|}
\hline \multirow{2}{*}{ Parameter } & \multicolumn{3}{|c|}{ Copper (Cu) } & \multicolumn{3}{|c|}{ Lead $(\mathrm{Pb})$} & \multicolumn{3}{|c|}{ Cadmium (Cd) } \\
\hline & $* 1$ & *2 & *3 & $* 1$ & *2 & *3 & $* 1$ & *2 & *3 \\
\hline $\begin{array}{l}\text { Concentration } \\
\text { of element }[\mu \mathrm{g} / \mathrm{l}]\end{array}$ & $\begin{array}{l}534.9 \\
\pm 15.7\end{array}$ & $\begin{array}{l}45.6 \\
\pm 6.4\end{array}$ & $\begin{array}{l}35.4 \\
\pm 5,2\end{array}$ & $\begin{array}{l}530.3 \\
\pm 14.1\end{array}$ & $\begin{array}{l}68.2 \\
\pm 8.5\end{array}$ & $\begin{array}{l}24.6 \\
\pm 2,6\end{array}$ & $\begin{array}{l}651.4 \\
\pm 18.8\end{array}$ & $\begin{array}{l}179.1 \\
\pm 8.3\end{array}$ & $\begin{array}{l}145.4 \\
\pm 6.1\end{array}$ \\
\hline Conductivity $[\mu \mathrm{S} / \mathrm{cm}]$ & $\begin{array}{l}60.4 \\
\pm 3.1\end{array}$ & $\begin{array}{l}178.7 \\
\pm 3.7\end{array}$ & $\begin{array}{l}171.1 \\
\pm 2.3\end{array}$ & $\begin{array}{l}62.7 \\
\pm 1.9\end{array}$ & $\begin{array}{l}104.8 \\
\pm 2.6\end{array}$ & $\begin{array}{l}97.3 \\
\pm 3.6\end{array}$ & $\begin{array}{l}60.8 \\
\pm 2.6\end{array}$ & $\begin{array}{l}118.6 \\
\pm 1.6\end{array}$ & $\begin{array}{l}125.3 \\
\pm 2.7\end{array}$ \\
\hline Redox potential [mV] & $\begin{array}{l}272 \\
\pm 17\end{array}$ & $\begin{array}{l}107 \\
\pm 10\end{array}$ & $\begin{array}{l}97 \\
\pm 8\end{array}$ & $\begin{array}{l}283 \\
\pm 26\end{array}$ & $\begin{array}{l}134 \\
\pm 13\end{array}$ & $\begin{array}{l}121 \\
\pm 16\end{array}$ & $\begin{array}{l}269 \\
\pm 30\end{array}$ & $\begin{array}{l}130 \\
\pm 14\end{array}$ & $\begin{array}{l}141 \\
\pm 10\end{array}$ \\
\hline $\mathrm{pH}[-]$ & $\begin{array}{c}6.07 \\
\pm 0.07\end{array}$ & $\begin{array}{c}9.09 \\
\pm 0.07\end{array}$ & $\begin{array}{c}9.21 \\
\pm 0.07\end{array}$ & $\begin{array}{c}5.19 \\
\pm 0.09\end{array}$ & $\begin{array}{c}7.82 \\
\pm 0.09\end{array}$ & $\begin{array}{c}9.00 \\
\pm 0.10\end{array}$ & $\begin{array}{c}8,06 \\
\pm 0.06\end{array}$ & $\begin{array}{c}8.35 \\
\pm 0,08\end{array}$ & $\begin{array}{c}8,87 \\
\pm 0,07\end{array}$ \\
\hline
\end{tabular}

$* 1$ - model sample before adsorption process, $* 2$ - control sample, $* 3$ - magnetized sample

in the magnetized samples was higher than for the copper and lead ion solution, while the redox potential was also lower in the magnetized copper and lead ions.

The lowest concentration value in the model solution prior to the process of adsorption, was obtained in the case of lead and amounted to $510.21 \mu \mathrm{g} / 1$ (Table 4), taking into account the control sample gave the lowest concentration value in the case of copper $(35.42 \mu \mathrm{g} / \mathrm{l})$. When analyzing the values of samples exposed to the magnetic field, the lowest value was obtained in the lead solution $(21.21 \mu \mathrm{g} / \mathrm{l})$. The highest values of the cadmium concentration were obtained in the sample prior to the adsorption process $(680.37$ $\mu \mathrm{g} / \mathrm{l})$, in the control samples as well as after the exposure to the magnetic field following the adsorption process; the lowest values were also obtained in a series of cadmium solutions. The obtained results of variance show that the most scattered results were obtained for the samples before the adsorption process in a series of cadmium solutions $(354.1 \mu \mathrm{g} / \mathrm{l})$. Controls after adsorption were characterized by the highest scattering around the mean for lead (variance of $71.9 \mu \mathrm{g} / \mathrm{l}$ ). In a series of MF samples after adsorption, the highest variance was obtained in a series of samples containing cadmium $(37.6 \mu \mathrm{g} / \mathrm{l})$.

Only in the case of cadmium ions, electrolytic conductivity and redox potential, the values were lower in control samples without the influence of magnetic field. The reason for $\mathrm{pH}$ increase of pu- rified water after the step associated with the activated alumina is the amphoteric nature of the material. When water comes into contact with $\mathrm{Al}_{2} \mathrm{O}_{3}$ on the surface, hydroxides that raise the $\mathrm{pH}$ of water flowing through the adsorbent bed are formed.

Many authors have tested the effectiveness of arsenic and fluoride ions removal on the activated alumina [Su et al. 2008; Lescano et al. 2015]. Su et al. (2008) tested the activated alumina applied to the removal of As (V), Se (IV), and V (V) from water, depending on different $\mathrm{pH}$ values and the sorbate load (Su et al. 2008). The scientific team of Naiyi (2009) conducted the application research using samples of industrial wastewater containing $\mathrm{Cd}$ (II) and $\mathrm{Pb}$ (II), which showed the usefulness of activated alumina for the wastewater purification of these metals. Kartinen and Martin (1995) carried out the pilot studies on the removal of arsenic from water containing As(III) at the level about $100 \mu \mathrm{g} / 1$, using activated alumina as an adsorbent. Their results indicate the potential of $50 \%$ reduction in the concentration of As, and in the case of oxidizing all As (III) to As (V) contained in the water, even a 70\% increase in the capacity of an adsorbent bed [Kartin, Martin 1995].

The second tested process MF is efficient, energy-saving, chemical-free, and environmental friendly. The analysis of the collected information, indicated that in the future, the influence of magnetic field on the physicochemical properties of water and properties of the sorption materials may be used more frequently and widely.

Table 4. The variance, minimum, maximum value of the results of element concentrations

\begin{tabular}{|l|c|c|c|c|c|c|c|c|c|}
\hline \multirow{2}{*}{ Parameter } & \multicolumn{3}{|c|}{ Copper $(\mathrm{Cu})$} & \multicolumn{3}{c|}{ Lead $(\mathrm{Pb})$} & \multicolumn{3}{c|}{ Cadmium $(\mathrm{Cd})$} \\
\cline { 2 - 12 } & $* 1$ & ${ }^{*} 2$ & ${ }^{*} 3$ & $* 1$ & ${ }^{*} 2$ & ${ }^{*} 3$ & $* 1$ & ${ }^{*} 2$ & ${ }^{*} 3$ \\
\hline Variance $[\mu \mathrm{g} / \mathrm{l}]$ & 246.9 & 40.3 & 27.2 & 198.5 & 71.9 & 6.7 & 354.1 & 69.0 & 37.6 \\
\hline Minimum value $[\mu \mathrm{g} / \mathrm{l}]$ & 515.6 & 35.4 & 29.5 & 510.2 & 58.9 & 21.2 & 621.8 & 165.4 & 136.2 \\
\hline Maximum value $[\mu \mathrm{g} / \mathrm{l}]$ & 555.3 & 54.5 & 44.9 & 550.1 & 80.1 & 29.1 & 680.3 & 190.3 & 154.3 \\
\hline
\end{tabular}

$* 1$ - model sample before adsorption process, $* 2$ - control sample, $* 3$ - magnetized sample 
In many cases, it restricts the use of chemicals and consumption of energy, which in many aspects contributes to the protection of the natural environment. It seems appropriate to investigate the mechanism of magnetic field effect on the process of adsorption on activated alumina. This sorbent has the ability to remove metals, anions, and other specimens present in the water. Furthermore, removal of these components is carried out by adsorption or chemical precipitation of formed hydroxides or complexes.

The changes in the adsorption efficiency of the investigated metals by the magnetic field on active alumina are shown in Figure 2. The highest efficiency of magnetic adsorption was obtained with a lead solution of $95.36 \%$, which is $8.22 \%$ greater than that of the control solution was without magnetic field (87.14\%). The lowest difference in adsorption efficiency, amounting to $1.90 \%$, was observed for copper ions. Considering the cadmium-containing model solution, the highest efficiency was obtained with a control solution of $72.52 \%$ and $77.67 \%$ with a magnetic field, resulting in $5.15 \%$ greater efficiency in the case of a magnetized sample.

The research conducted by the Genç-Fuhrman research group (2007) has shown that the 11 most potential sorbents of the filter bed for secondary rainwater treatment of heavy metals including $\mathrm{Cd}$ and $\mathrm{Cu}$ are the best active alumina. The studies were also carried out on rainwater model solutions. The water after the adsorption process on active alumina also had an elevated $\mathrm{pH}$. The work of the Yan research group (2016) provides a systematic comparison of different adsorbents for remediation of metallurgical industry wastewa- ter containing high concentrations Cd. Out of the four adsorbent media evaluated, involving $\mathrm{TiO}_{2}$, AA, GFO, and nZVI, $\mathrm{TiO}_{2}$ is the most efficient adsorbent due to its unique features: high adsorption capacity, wide applicable $\mathrm{pH}$ range, full regenerability, and great chemical stability. According to the research team of Hao, the application of the MF increases the adsorption capacity and affects the behaviour of sorbent - organic bentonite [Hao et al. 2012]. The MF also improves the adsorption capacity of metallic iron that is also often used as a sorbent for removing various components from aqueous solutions. The studies on the removal of selenium Se (VI) from water during the process of adsorption on metallic iron due to the presence of a weak MF revealed an increased rate of Se (VI) removal. In the case where the selenium removal occurs on metallic iron, the $\mathrm{pH}$ range increased from 4.0-6.0 to 4.0-7.2. The use of MF in order to increase the selenium removal by metallic iron is promising and environmentally friendly process, since it does not require additional energy and expensive reagents [Liang et al. 2014]. Other researchers tested the increased efficiency of arsenic As (III) and As (V) adsorption under the influence of magnetic field also on metallic iron [Sun et al. 2014]. The experiment indicating that MF can significantly enhance the arsenic removal by metallic iron, even in the presence of various cations and anions was performed by Sun et al. (2014). The authors confirmed that applying the MF accelerates the conversion of arsenic from (III) onto (V) at the interphase solution-solid within $\mathrm{pH}$ range 5.0-9.0 and improves the oxidation of As (III) to (V) in solution of pH 3.0. Kim et al. (2011) reported that

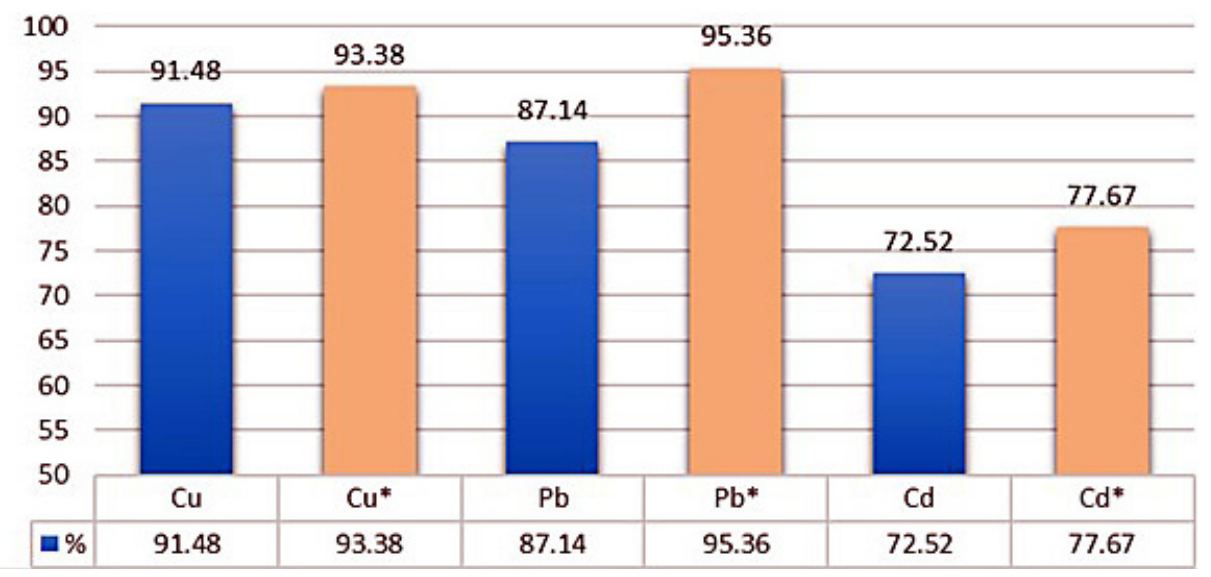

Figure 2. Adsorption efficiency of $\mathrm{Cu}, \mathrm{Pb}, \mathrm{Cd}$ in the activated alumina - control and magnetized sample *- magnetized sample 
magnetic field applied $(\leq 40 \mathrm{mT})$ for metallic iron suspension considerably increases the removal of 4-chlorofenol from $26 \%$ up to $54 \%$. The research team of $\mathrm{Li}$ (2016) tested the impact of magnetic field on the adsorption of methylene blue pigment on the material obtained from the wheat hay pyrolysis, and the efficiency of the PM effect on pigment adsorption was confirmed.

Depending on the physicochemical parameters water should have, different methods are used to remove individual components of the solution. The adsorption on various packings (sorbents) is a frequently used process. Adsorption, in terms of the mechanism, is divided into physical and chemical while taking into account the way the process is conducted, dynamic and static adsorptions are distinguished. Viscous forces determine the retaining of the sorbent particles in a given bed. The phenomenon that also determines the adsorption effects is attracting the removed particles to the grains of the sorption bedding. The effectiveness of this phenomenon is the result of attraction and repulsion forces, and it largely depends on the size and zeta potential of the removed particles and grains of the sorption material, as well as the ionic strength of the processed solution. The research team of Toledo (2008) proved that the magnetic field remarkably affects the physicochemical parameters of water, including viscosity. Thus, applying the magnetic field can have a significant impact on the effectiveness of physical adsorption. Meanwhile, chemical adsorption consists in binding the molecules of the adsorbate (particles of contaminant) in the active sites of the adsorbent. The adsorbate particles can be maintained on the sorbent surface (activated carbon bed or other suitable absorbent, e.g. activated aluminum oxide) by such forces as hydrogen bonding, dipole-dipole interactions, van der Waals, and electrostatic forces. Magnetic field significantly affects the cleavage of hydrogen bonds between water molecules. The magnetic field affects the competitiveness of intra and intermolecular hydrogen bonds, which entails a weakening of large structures and the formation of small structures with stronger hydrogen bonds within the water clusters that can be easily bound to other molecules, e.g. on a surface of the potential sorbent [Toledo et al. 2008]. Sorption as a primary process, or intensified by the action of other factors, is effectively used to remove various substances from water and aqueous solutions, from relatively simple to hardly removable complex organic compounds.
The influence of the magnetic field on the heavy metal adsorption process on active alumina can be explained by the application of magnetic field as a factor causing changes in the structure of water and aqueous solutions, which results in changes in the solution viscosity, surface tension, and the vaporization enthalpy, leading to a change in the process of solution components adsorption on activated aluminum oxide. The research planned within the project will determine the nature of the changes and mechanism of the magnetic field effect on the changes in the process of adsorption on activated aluminum oxide. The magnetic field itself is a state of a space or area where magnetic forces act on the moving electric charges, and objects having a magnetic momentum, regardless of their movement. These forces are a special type of interaction, taking place at a distance, associated with the presence of charged particles, magnets, or carriers, in which electric current flows. Water is a dipole having an uneven distribution of electric charge in the molecule, which causes the magnetic field to affect water in a certain manner and changes its properties. The changes in the properties of water are translated into a change of the molecular interactions between the water molecules and molecules or ions of other compounds. Magnetic field can also interact with the mechanism of adsorption process by changing the physicochemical properties of water and aqueous solution subjected to this process.

\section{CONCLUSIONS}

1. Activated alumina showed high adsorption capacity of the tested heavy metals, as confirmed by other researchers. It has been shown that the magnetic field has a positive influence on $\mathrm{Cu}$, $\mathrm{Pb}$, and $\mathrm{Cd}$ adsorption.

2 . The observed increase of the heavy metal removal efficiency in the samples exposed to magnetic field varied from $1.9 \%$ to $8.2 \%$ compared to the control samples. The highest efficiency of magnetic adsorption was obtained with a lead solution of $95.36 \%$, which is $8.22 \%$ greater than that of the control solution was without magnetic field $(87.14 \%)$. The lowest difference in the adsorption efficiency, which was $1.90 \%$, was observed for copper ions. Copper ion adsorption efficiency was $91.48 \%$ in the control solution and $93.38 \%$ in the solution treated with magnetic field. 
3. The biggest increase in the adsorption under the influence of the magnetic field was found in the case of lead. The magnetized samples of lead solutions after adsorption were characterized by the smallest diffusion around the mean (variance $6.7 \mu \mathrm{g} / \mathrm{l}$ ).

4. The results of this study indicated that the combined magnetic field and adsorption process has a significant role in water treatment technology. MF is efficient, energy-saving, chemical-free, and environmental friendly. The analysis of the collected information showed that in the future, the influence of magnetic field on the physicochemical properties of water and the properties of the sorption materials may increase. It can be used more often and widely, thus contributing to the optimization of water treatment processes.

\section{Acknowledgements}

The research was carried out within the scope of work no. MB/WBiIŚ/10/2016 and financed from funds for works for the development of young researchers and $\mathrm{PhD}$ students of Ministry of Science and Higher Education.

\section{REFERENCES}

1. Dhanasekaran P., Satya Sai P.M., Anand Babu C., Krishna Prabhu R., Rajan K.K. 2016. Arsenic removal from groundwater by Anjili tree sawdust impregnated with ferric hydroxide and activated alumina. Water Science and Technology: Water Supply, 16(1), 115-127.

2. Ferreira De Brito, J., De Oliveira Ferreira, L., Ragozoni Pereira, M.C., Paulo Da Silva, J., Ramalho, T.C. 2012. Adsorption of aromatic compounds under magnetic field influence, Water, Air, and Soil Pollution, 223(6), 3545-3551.

3. Genç-Fuhrman H., Mikkelsen P.S., Ledin A. 2007. Simultaneous removal of $\mathrm{As}, \mathrm{Cd}, \mathrm{Cr}, \mathrm{Cu}, \mathrm{Ni}$ and $\mathrm{Zn}$ from stormwater: Experimental comparison of 11 different sorbents, Water Research 41(3), 591-602.

4. Hao X., Liu H., Zhang G., Zou H., Zhang Y., Zhou M., Gu Y. 2012. Magnetic field assisted adsorption of methyl blue onto organo-bentonite, Applied Clay Science, 55, 2012, 177-180.

5. Naiya, T. K., Bhattacharya, A. K., Das, S. K. 2009. Adsorption of $\mathrm{Cd}(\mathrm{II})$ and $\mathrm{Pb}$ (II) from aqueous solutions on activated alumina. Journal of Colloid and Interface Science, 333(1), 14-26.
6. Kırbıyık, C.., Pütün, A.E., Pütün, E. 2016. Comparative studies on adsorptive removal of heavy metal ions by bio sorbent, biochar and activated carbon obtained from low cost agro-residue. Water Science and Technology, 73(2), 423-436.

7. Li G., Zhu W., Zhang C., Zhang S., Liu L., Zhu L., Zhao W. 2016. Effect of a magnetic field on the adsorptive removal of methylene blue onto wheat straw biochar, Bioresource Technology, 206, 16-22.

8. Liang L., Sun W., Guan X., Huang Y., Choi W., Bao H., Li L., Jiang Z. 2014. Weak magnetic field significantly enhances selenite removal kinetics by zero valent iron, Water Research, 49, 371-380.

9. Singh, T.S., Pant, K.K. 2004. Equilibrium, kinetics and thermodynamic studies for adsorption of As(III) on activated alumina. Separation and Purification Technology, 36(2), 139-147.

10. Sun Y. Guan X., Wang J., Meng X., Xu C., Zhou G. 2014. Effect of Weak Magnetic Field on Arsenate and Arsenit from Water by Zerovalent Iron: An XAFS Investigation, Environmental Science \& Technology, 48, 6850-6858.

11. Hering J. G., Chen P., Wilkie J. A., Elimelech M., Liang S. 2004. Arsenic removal from drinking water during coagulation, American Water Works Association. 96, 106-114.

12. Mc Neill L.S., Edwards M. 1995. Predicting arsenic removal during metal hydroxide precipitation, American Water Works Association, 87(4), 105-113.

13. Kim D.H., Kim J., Choi W. 2011. Effect of magnetic field on the zero valent iron induced oxidation reaction, Journal of Hazardous Materials, 192(2), 928-931.

14. Davis S.A., Misra, M. 1997. Transport model for the adsorption of oxyanions of selenium (IV) and arsenic (V) from water onto lanthanum-and aluminum-based oxides, Journal of Colloid and Interface Science, 188(2), 340-350.

15. EPA 2007. Removing Multiple Contaminants from Drinking Water: Issues to Consider, EPA, 816-H07-004.

16. Kartin Ch., Martin J. 1995. An overview of arsenic removal processes, Desalination, 103(1-2), 79-88.

17. Toledo E.J.L., Ramalho T.C., Magriotis Z.M. 2008. Influence of magnetic field on physical-chemical properties of the liquid water: Insights from experimental and theoretical models, Journal of Molecular Structure, 888, 409-415.

18. Yan L., Wang W., Li X., Duan J., Jing Ch. 2016. Evaluating adsorption media for simultaneous removal of arsenate and cadmium from metallurgical wastewater, Journal of Environmental Chemical Engineering, 4(3), 2795-2801. 